\title{
Data Transmission Unit and Web Server Interaction to Monitor Water Distribution: A Cyber-Physical System Perspective
}

\author{
Abhishek $\mathrm{MB}^{\#}$ and N Shekar V Shet ${ }^{\#}$

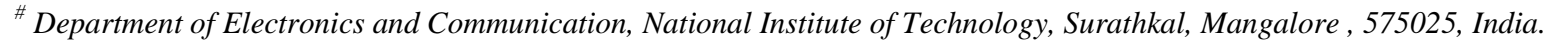 \\ E-mail:abhishek.mb@gmail.com,shet@nitk.ac.in.
}

\begin{abstract}
Cyber-Physical System (CPS) is the concept of converging physical devices with cyber systems, CPS shares environmental information globally and improves resource utilization. The major aim of our work is to use the CPS technology to overcome improper handling and care of water supply infrastructure. Our experimental water pipileing infrastructure test bed set up at National Institute of Technology Karnataka Surathkal (NITK), India includes analysis of water distribution in three storage tanks using minimal wireless communication technology. This requires monitoring and wireless networking of the monitored data. In order to obtain water usage of each storage tanks, we have proposed low cost customization of water pipeline infrastructure. Monitoring unit (MU) includes 865-867Mhz RF module. In this paper, we deal with the networking part of CPS to perform water monitoring distribution in each storage tanks. Networking of CPS includes communication between Data transfer unit (DTU) and Aggregator unit (AU) used in the MU and also communication between DTU and web server unit (WS). Communication between DTU and AU involves analyzing the amount of water flow in the Inlet and Outlet of storage tanks in the campus. The WS unit contains resultant data of water usage in each storage tanks. The extensive group of resultant data sets of water usage, obtained in each storage tanks, gives importance to data analytics. Initially, we came up with a small-scale experimental set up at NITK campus; which is then extended to large scale area. The waterflow rate graphs show average daily and monthly usage of water of each storage tank.
\end{abstract}

Keywords - cyber-physical system; data transfer unit; aggregator; meter interface unit; monitoring unit; web server.

\section{INTRODUCTION}

In recent years, water is considered as one of the valuable resources in INDIA, due to many reasons such as rapidly increasing population, pollution and lack of bulk water supply infrastructure. In INDIA as shown in Fig. 1, there is a huge scarcity of water resources to meet the basic needs of the population in India. A continuous supply of water is almost impossible. Even though a water service provider can manage demand for water using a system under continuous supply conditions, there is a minimum per capita demand for water for basic living needs. Supply and demand management is essential for the efficiency of a water service provider. Supply management denotes the activities that manage water on the supply end of a water service provider. Demand management denotes the activities used for the reduction of water usage by customers. The operation of water distribution service for continuous water supply is not effectively managed in India. Water supply provided is said to be continuous if water is delivered to every customer continuously in every day throughout the year, using an effective water distribution system [1].So in our experiment, we are customizing existing water pipeline infrastructure, in order to monitor water distribution to practice demand management. Storing water and preventing unbalanced water consumption are the major challenge in water management research. Effective steps need to be taken to control and reduce the water wastage from end users as well as from water resources. Undetected water leak in a pipe leads to huge water loss [2]. Thus, identifying the water leak in prior, by the aid of water management system decided improves balanced water utilization. For several years, water pipelines are deployed and maintained by human interventions, such as turning off or turning on valves of water pipes. It is known that the chance of water wastage is more because humans are prone to make mistakes. Thus, in this paper we come up with a water management system that monitors the water utilization in storage tanks, our experiment is done with available water pipeline infrastructure. By the help of this water monitoring system, water distribution can be tracked, and the amount of water consumed by the end user can be recorded. In our experiment set up, [3] customization of the existing water pipeline has been done to check up the water inflow and outflow details in storage tanks. In coming days,[4] [5] Cyber-physical system will become necessary to the human species, since wired control is bulky, uneconomical, requires large labor work and difficult to maintain. [6] Cyber- 
physical system, Internet of things and IPV6 envisages addressing every grain of sand on the surface of this planet with a unique ID. In this paper, we are considering the networking part of CPS to perform monitoring of water distribution system in storage tanks and discussing the communication between DTU and web server using minimal wireless technology.

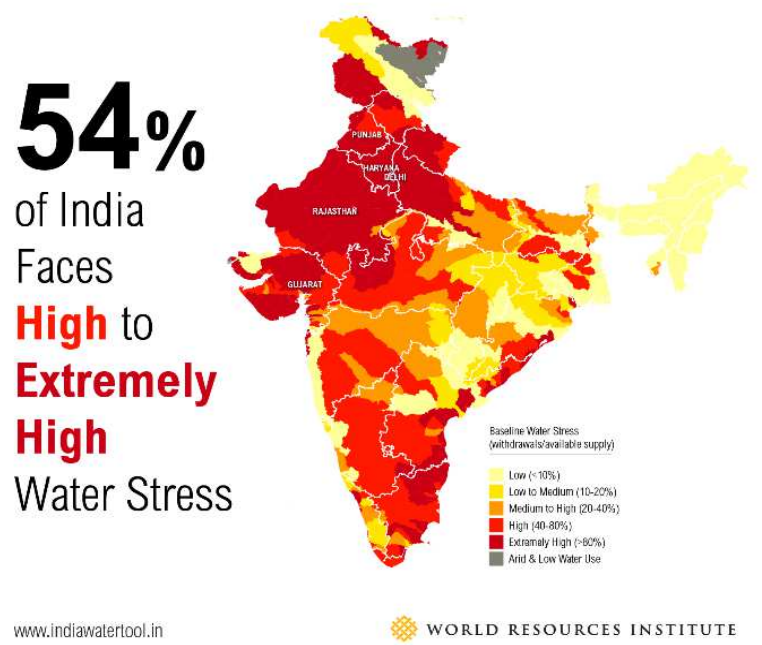

Fig. 154 percent of India's total area facing high to extremely high water stress. Source: www.wri.org/ http://www.indiawatertool.in/

\section{MATERIALS AND METHODS}

\section{A. Cyber Physical System}

The term cyber-physical systems (CPS) was coined by Helen Gill at the National Science Foundation in the U.S. to refer to the integration of computation with physical processes [7]. Cyber-Physical Systems (CPS) are engineered systems whose operations are controlled by a computing and communication core. The desired characteristics of a welldesigned CPS are a connected and coordinated distribution, robustness and responsiveness, adaptability, safety, and usability, with feedback loops including humans and the environment. This coordination between cyber and physical systems will be manifested from nano-scale to large-scale systems of systems [8].

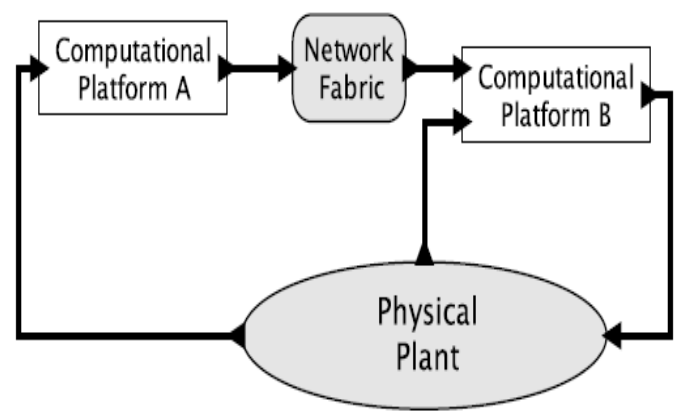

Fig. 2 Simple structure to understand CPS. [9]

Fig. 2 shows the simple structure of CPS [9]. Here, two platforms communicate with Physical plant through wireless devices like sensors, RF, and actuators and with each other through a network fabric. Platform B controls the physical plant via computation (sensor, RF, and actuators). Platform A makes additional measurements via computational (sensor,
$\mathrm{RF}$, and actuators) and sends the changes to Platform B through network fabric and controls the physical plant. So, it will be acting as a feedback control loop. [10].

Few of application of CPS include [11], [12]

- Healthcare

○ Surgery is done with real-time image guidance.

- Analgesia inclusion pump controlled by patient.

- Connectivity of medical devices using wireless technologies devices can be improved.

- Surgery is done with the help of robotics.

- Automotive

- With the use of sensors, accidents can be avoided.

- Traffic congestion problem can be reduced.

- By using a set of CPS techniques that can control autonomous vehicles providing the best possible routes, reducing accidents, death caused by human being

- With the help of CPS techniques, vehicles can be controlled by providing them facilities like routes, minimizing driver interaction in accidents and so on.

- Smart Power Grid

- Monitoring the usage of charging and discharging of transformers in an electrical substation.

- In a Smart grid system, balancing the power flow can be done.

- Security attacks can be provided for energy infrastructure from outsiders.

- Avionics,

- Automation of Factory and Smart home management system, and soon.

\section{B. $865-867 \mathrm{Mhz}$ RF module}

In this work, we have used [13] 865-867 MHz RF module which provides robust wireless communication for all conditions [3]. The main advantage of this module is that with the help of serial data interface the module is suitable for adding wireless capability to any embedded devices. Other advantages include minimal power and provide reliability of data deliveries between devices.

The main features of this device are [13]:

- Supports point to point, point to multipoint and mesh topologies. (Here, star network is established).

- $\quad$ Support 2 FSK, 2-GFSK.

- Configurable transmit power up to $10 \mathrm{dBm}$.

- Maximum RF data rate is 500kbps.

- Data reliability, acknowledgment mode communication, is used

- Source/Destination is addressing.

- Unicast and Broadcast communication.

- Analog to Digital conversion and Digital I/O line support.

- $\quad$ Power saving modes. 
TABLE I.

SPECIFICATION OF 865-867 MHz RF MODULE [13]

\begin{tabular}{|c|c|c|}
\hline SL Num & Parameter & Details \\
\hline 1 & \multicolumn{2}{|l|}{ Power } \\
\hline i) & Supply Voltage & 2.4 to $3.6 \mathrm{~V}$. \\
\hline ii) & Transmit Current & $\begin{array}{l}\text { 20mA@0dBm, } \\
35 \mathrm{~mA} @ 10 \mathrm{dBm} .\end{array}$ \\
\hline iii) & Idle/Receive Current & $20 \mathrm{~mA}$. \\
\hline iv) & Power-down Current & $<10$ micro A. \\
\hline 2 & \multicolumn{2}{|l|}{ General } \\
\hline i) & Frequency & $865-867 \mathrm{MHz}$. \\
\hline ii) & $\begin{array}{l}\text { Nominal } \\
\text { Power }\end{array}$ & $10 \mathrm{dBm}$ \\
\hline iii) & RF Data Rate & $\begin{array}{l}2.4 \mathrm{kbps} \text { to } \\
500 \mathrm{kbps}(\mathrm{Max}) \text {. }\end{array}$ \\
\hline iv) & Receiver Sensitivity & $\begin{array}{l}-106 \mathrm{dBm}(\text { at } 9600 \\
\text { baud). }\end{array}$ \\
\hline v) & Serial Data Rate & Up to 115200 baud. \\
\hline vi) & Operating temperature & -40 to $85{ }^{0} \mathrm{C}$ \\
\hline vii) & $\begin{array}{l}\text { Antenna } \quad \text { Connector } \\
\text { options }\end{array}$ & MMCX. \\
\hline viii) & On-board Antenna & Spring Antenna. \\
\hline 3 & Network & \\
\hline i) & $\begin{array}{ll}\text { Supported } & \text { network } \\
\text { topologies } & \end{array}$ & $\begin{array}{l}\text { Point to point, point to } \\
\text { multipoint, mesh } \\
\text { topologies. }\end{array}$ \\
\hline ii) & Addressing options & PAN ID and addresses. \\
\hline 4 & Mechanical & \\
\hline i) & Dimension & $36 \mathrm{~mm} * 26 \mathrm{~mm}$ \\
\hline ii) & Interface connector & $\begin{array}{l}2 * 10 \text { pin berg stick, } \\
2.00 \mathrm{~mm} \text { pitch. }\end{array}$ \\
\hline
\end{tabular}

Source: www.melangesystems.com.

\section{Proposed Experimental Set up}

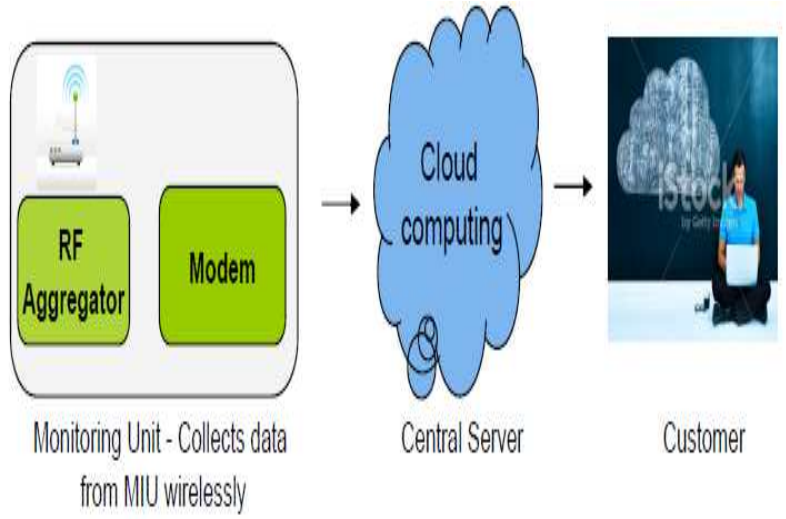

Fig. 3 Monitoring Unit. [2]

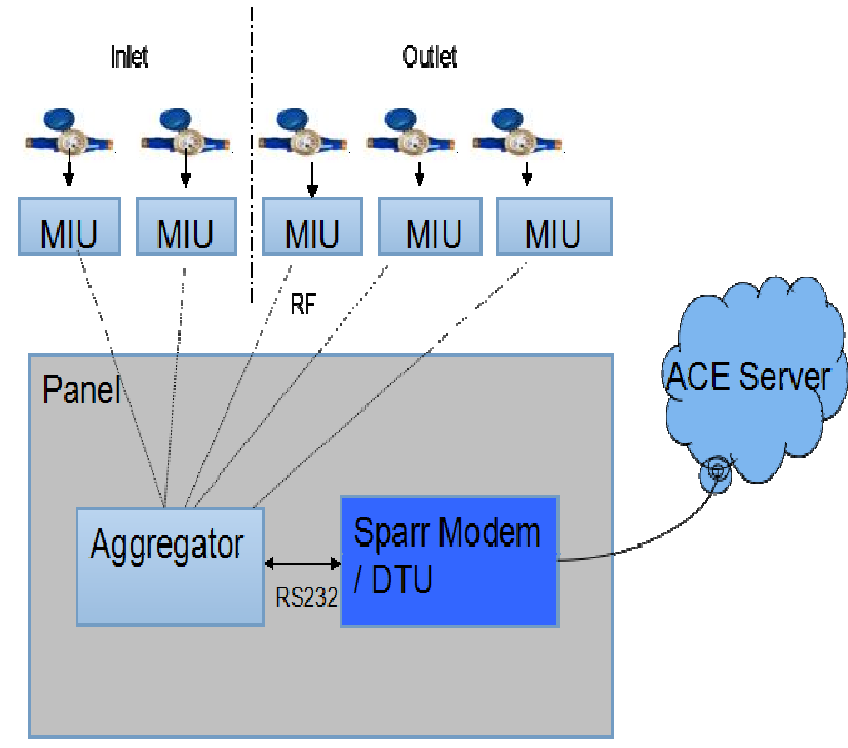

Fig. 4 Communication between MIU, Aggregator, DTU and Web server.

Fig. 3 shows the pictorial representation of monitoring unit which includes aggregator, DTU and web server. In each storage tank consists of MIU which includes water meter interfaced with a reed switch and an RF module to read water inflow and outflow details [3]. In the monitoring unit as shown in Fig. 4 is used to develop an automation solution that reads the water inflow and outflow parameters from each storage tank. Aggregator receives the water inflow and outflow parameters from each storage tank. An aggregator is interfaced to DTU with RS 232 port as shown in Fig 4. DTU is interfaced with an aggregator to read water inflow and outflow details and transmit the respective information to web server. Each storage tank will have one DTU, and DTU will collect information about water flow details from both inlet and outlet of the storage tank. For every 15 minutes, based on the water inflow and outflow details, DTU shall calculate the Water Pulse count for each Inlet ,Water Pulse count for each Outlet ,Total Pulse count for Inlet, Total Pulse count for Outlet, Net Volume of the storage tank. Finally, in ACE web [14], all the resulting information collected in DTU will be displayed.

\section{Communication between DTU, Aggregator and web server}

TABLE II.

PRE-DEFINED MIU ADDRESS TABLE [14]

\begin{tabular}{|c|c|}
\hline MIU & Address \\
\hline Inlet 1 & 0x00000001 \\
\hline Inlet 2 & 0x00000002 \\
\hline Inlet 3 & 0x00000003 \\
\hline Inlet 4 & 0x00000004 \\
\hline Inlet 5 & 0x00000005 \\
\hline
\end{tabular}




\begin{tabular}{|c|c|}
\hline Outlet 1 & 0x00000006 \\
\hline Outlet 2 & 0x00000007 \\
\hline Outlet 3 & 0x00000008 \\
\hline Outlet 4 & 0x00000009 \\
\hline Outlet 5 & 0x0000000A \\
\hline
\end{tabular}

1) Device Identification Message: The Device ID to include in the Device Identification message of DTU [14]. Example to understand Device Identification Message is shown below

i) Request Byte Stream Format

3CA100000001131000000000000014C02EF0F0010001000 000025B3E

ii) Byte Stream Format Split View

3C|A100|00|00|01|13|1000000000000014|C02E|F0|F001|000 $1|00000002| 5 \mathrm{~B} \mid 3 \mathrm{E}$

TABLE III.

REQUeST Byte STREAM FoRMAT [14]

\begin{tabular}{|c|l|c|}
\hline $\begin{array}{c}\text { Message } \\
\text { header }\end{array}$ & Description & $\begin{array}{c}\text { Length } \\
\text { (bytes) }\end{array}$ \\
\hline 3C & Start byte (constant) & 1 \\
\hline A100 & Message code (constant) & 2 \\
\hline 0 & Status, 0 - Success, >0 - Error & 1 \\
\hline 0 & $\begin{array}{l}\text { Indicates the total number of responses that } \\
\text { shall follow the current message stream }\end{array}$ & 1 \\
\hline 1 & No of parameters in this message (constant) & 1 \\
\hline 13 & Total number of bytes following this (constant) & 1 \\
\hline 100000000 & Device ID & 8 \\
\hline 0000014 & Device type & 2 \\
\hline F0 & $\begin{array}{l}\text { Constant Value for Device Identification Data } \\
\text { Packet }\end{array}$ & 1 \\
\hline F001 & Constant & 2 \\
\hline 0001 & Parameter code (constant) & 2 \\
\hline 00000002 & Application ID & 4 \\
\hline 56 & $\begin{array}{l}\text { FCS (^ operation on all message heads } \\
\text { excluding the Start and Stop Bytes) }\end{array}$ \\
\hline $3 \mathrm{E}$ & Stop byte & 1 \\
\hline & & \\
\hline
\end{tabular}

\section{2) Water Meter Parameters Message}

i) Request Byte Stream Format

3CA10003000D0B07DC0F05050007371000000000002001 C02E01F02000010002000B000C00150018001B000043210 00012340000456300003214000023130000 ACFD000A4321 $\mathrm{xx} 3 \mathrm{E}$

ii) Byte Steam Format Split View

3C|A100|03|00|0D0B07DC0F0505|00|07|37|1000000000002 001|C02E|01|F020|0001|0002|000B|000C|0015|0018|001B|0
0004321000012340000456300003214000023130000 ACFD $000 \mathrm{~A} 4321 \times x 3 \mathrm{E}$

TABLE IV.

REQUEST BYTE STREAM FORMAT

\begin{tabular}{|c|c|c|c|}
\hline $\begin{array}{l}\text { Message } \\
\text { header }\end{array}$ & Description & \begin{tabular}{|l|}
$\begin{array}{l}\text { Length } \\
\text { (bytes) }\end{array}$ \\
\end{tabular} & Type \\
\hline $3 \mathrm{C}$ & Start byte (constant) & 1 & Int \\
\hline A100 & Message code (constant) & 2 & Int \\
\hline 03 & $\begin{array}{l}\text { Status: } 3 \text { - Message with Retry } \\
\text { counter and Timestamp }\end{array}$ & 1 & Int \\
\hline 00 & Retry counter & 1 & Int \\
\hline $\begin{array}{l}\text { 0D0B07D } \\
\text { C0F0505 }\end{array}$ & $\begin{array}{l}\text { Time stamp in format } \\
\text { DDMMYYYYHHMMSS (all in } \\
\text { hex) }\end{array}$ & 7 & Int \\
\hline 00 & $\begin{array}{l}\text { Indicates the total number of } \\
\text { responses that shall follow the } \\
\text { current message stream }\end{array}$ & 1 & Int \\
\hline 07 & $\begin{array}{l}\text { No of parameters in this message } \\
=4+\text { Inlet } 1+\text { Inlet } 2+\text { Outlet } 1+ \\
\text { Outlet } 2 \text { and so on }\end{array}$ & 1 & Int \\
\hline 37 & $\begin{array}{l}\text { Total number of bytes following } \\
\text { this (Sum of bytes from Device } \\
\text { ID to Meter Alarm status value) }\end{array}$ & 1 & Int \\
\hline $\begin{array}{l}100000000 \\
0002001\end{array}$ & Device ID & 8 & Int \\
\hline $\mathrm{C} 02 \mathrm{E}$ & Device Type & 2 & Int \\
\hline 01 & Constant & 1 & Int \\
\hline F020 & Constant & 2 & Int \\
\hline 0001 & Parameter code for Inlet 1 & 2 & Int \\
\hline \multirow[t]{2}{*}{0002} & Parameter code for Inlet 2 & 2 & Int \\
\hline & And so on. & & \\
\hline 0003 & Parameter code for Outlet 1 & 2 & Int \\
\hline \multirow[t]{2}{*}{0004} & Parameter code for Outlet 2 & 2 & Int \\
\hline & And so on. & & \\
\hline 0005 & Parameter code for Total Inlet & 2 & Int \\
\hline 0007 & Parameter code for Total Outlet & 2 & Int \\
\hline 0008 & Parameter code for Net Volume & 2 & Int \\
\hline 0101 & $\begin{array}{l}\text { Parameter code for Meter Alarm } \\
\text { value }\end{array}$ & 2 & Int \\
\hline 004A1C44 & Inlet 1 & 4 & Float \\
\hline \multirow[t]{2}{*}{ 0000DE44 } & Inlet 2 & 4 & Float \\
\hline & And so on. & & \\
\hline 0080EFD0 & Outlet 1 & 4 & Float \\
\hline \multirow[t]{2}{*}{ 00088B80 } & Outlet 2 & 4 & Float \\
\hline & And so on. & & \\
\hline 00000036 & Total Inlet & 4 & Float \\
\hline 00003296 & Total Outlet & 4 & Float \\
\hline 0000FF69 & Net Volume & 4 & Float \\
\hline 00 & Meter Alarm status value & 1 & Int \\
\hline $8 \mathrm{~F}$ & $\begin{array}{l}\mathrm{FCS}(\mathrm{XOR} \wedge \text { operation on all } \\
\text { message heads excluding the Start } \\
\text { and Stop Bytes) }\end{array}$ & 1 & Int \\
\hline $3 \mathrm{E}$ & Stop byte & 1 & Int \\
\hline
\end{tabular}




\section{3) Response Byte Stream Format:}

DTU shall wait for the acknowledgment from the server after sending the message. The server sends either a SUCCESS or FAILURE message. The Response sent out by Web server shall be either Success or Failure as shown in Table V and Table VI respectively. The Byte Stream Format shall be as below

- Success: 3CA1000000A13E

- Failure: 3CA1000200A33E

i) Success: $3 \mathrm{C}|\mathrm{A} 100| 00|00| \mathrm{A} 1 \mid 3 \mathrm{E}$

TABLE V.

SUCCESS RESPONSE BYTE STREAM FORMAT

\begin{tabular}{|c|c|c|}
\hline $\begin{array}{c}\text { Message } \\
\text { header }\end{array}$ & Description & $\begin{array}{c}\text { Length } \\
\text { (bytes) }\end{array}$ \\
\hline $3 \mathrm{C}$ & Start byte (constant) & 1 \\
\hline A100 & Message code (constant) & 2 \\
\hline 0 & Status: 0 - Success & 1 \\
\hline 0 & $\begin{array}{c}\text { Indicates the total number of responses that } \\
\text { shall follow the current message stream }\end{array}$ & 1 \\
\hline A1 & $\begin{array}{c}\text { FCS (^ operation on all message heads } \\
\text { excluding the Start and Stop Bytes) }\end{array}$ & 1 \\
\hline $3 \mathrm{E}$ & Stop byte \\
\hline
\end{tabular}

ii) Failure: $3 \mathrm{C}|\mathrm{A} 100| 02|00| \mathrm{A} 3 \mid 3 \mathrm{E}$

TABLE VI.

FAILURE RESPONSE BYTE STREAM FORMAT

\begin{tabular}{|c|c|c|}
\hline $\begin{array}{c}\text { Message } \\
\text { header }\end{array}$ & Description & $\begin{array}{c}\text { Length } \\
\text { (bytes) }\end{array}$ \\
\hline $3 \mathrm{C}$ & Start byte (constant) & 1 \\
\hline A100 & Message code (constant) & 2 \\
\hline 02 & Status: $>0$ - Error & 1 \\
\hline 00 & $\begin{array}{c}\text { Indicates the total number of responses } \\
\text { that shall follow the current message } \\
\text { stream }\end{array}$ & 1 \\
\hline A3 & $\begin{array}{c}\text { FCS (^ operation on all message heads } \\
\text { excluding the Start and Stop Bytes) }\end{array}$ & 1 \\
\hline $3 \mathrm{E}$ & \multicolumn{2}{|c|}{ Stop byte } \\
\hline
\end{tabular}

\section{RESULTS AND DISCUSSION}

The communication in the monitoring unit has been achieved successfully. The connection between DTU, aggregator and web server are working as needed. The request and response byte stream format for success and failure messages are communicated accurately between DTU and web server. Finally, we are able to display the water flow details from the inlet and outlet and also the net volume of the storage tank in the web server as shown in Fig. 5 and
Fig. 6. With the available water flow data, we have the following strategies towards data analytics. In Fig. 5, we are monitoring the monthly usage in a single storage tank. In Fig. 6 , we are monitoring the daily usage in a single storage tank. Since data analytics plays a significant role in computing and actuation part of CPS, We hope that these challenges and issues bring enough motivation for future discussions and interests of research work on CPS.

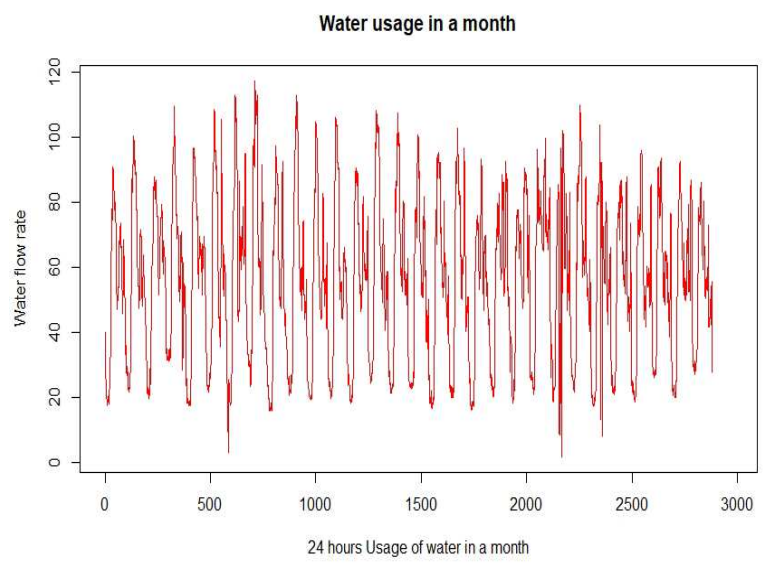

Fig. 5. Monthly usage of water in a Storage Tank.

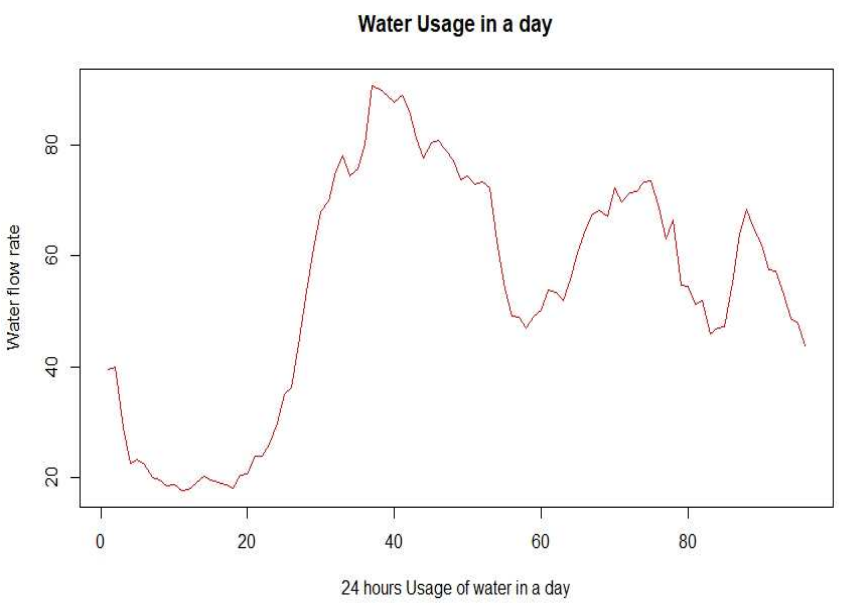

Fig. 6. 24 hours Usage of water in Storage Tank

\section{CONCLUSIONS}

The contents of this paper acknowledges the data interaction between Data Transmission Unit and web server. This paper has greatly deliberated on networking part of CPS. The extensive group of data sets obtained in each storage tanks gives importance to data analytics. Data analytics plays a major role which contributes for the promotion of CPS integration in campuses. The future work is planned towards CPS simulation by building data analytics model which ensures proper water management.

\section{ACKNOWLEDGMENT}

We would like to thank "Centre of Excellence for Wireless Sensor Networks" and Department of Electronics and Communication, NITK, Surathkal Mangalore, India for their support and encouragement for the research presented in this paper. Further, the Authors would like to acknowledge the discussion, work, and guidance given by 
Thought focus, Bangalore, especially Naveen Kumar Panguluri, and Ravi Kumar who were responsible for the installation of all devices.

\section{REFERENCES}

[1] Water for a sustainable world, The United Nations World Water Development Report 2015.

[2] Harrison E. Mutikanga, Saroj K. Sharma, and Kalanithy Vairavamoorthy, "Methods and Tools for Managing Losses in Water Distribution Systems," Journal of Water Resources Planning And Management, vol 139, ASCE, April 2013.

[3] Abhishek MB, N. Shekar V. Shet, "Wirelessly monitoring of water usage in smart campus: A CPS perspective," International Engineering Symposium, Japan, 2017

[4] Kaur, Kamaldeep, and L. T. JayPrakash. "Modeling and simulation of Cyber Physical Systems: A case of an adaptive water management system." Confluence The Next Generation Information Technology Summit (Confluence), 2014 5th International Conference-. IEEE, 2014

[5] Imen, Sanaz, and Ni-Bin Chang. "Developing a cyber-physical system for smart and sustainable drinking water infrastructure management." Networking, Sensing, and Control (ICNSC), 2016 IEEE 13th International Conference on. IEEE, 2016
[6] Wang, Zhaohui, et al. "Cyber-physical systems for water sustainability: challenges and opportunities." IEEE Communications Magazine ,2015

[7] Lee, Edward A., and Sanjit A. Seshia. "Introduction to Embedded Systems, A Cyber-Physical Systems Approach. 2011." UR L http://LeeSeshia. org 6: 18.

[8] Clas Jacobson, Cyber Physical Systems, ERCIM, April 2014.

[9] Edward A. Lee, "The Past, Present, and Future of Cyber-Physical Systems: A Focus on Models," Sensors, 2015.

[10] Edward Ashford Lee, Sanjit Arunkumar Seshia, Introduction to Embedded Systems:A Cyber-Physical Systems Approach, 2nd edition, LeeSeshia.org, 2015.

[11] Jiafu Wan, Min Chen, Feng Xia, Di Li, and Keliang Zhou, From Machine-to-Machine Communications towards Cyber-Physical Systems, ComSIS, Vol 10, 2013.

[12] Chih-Yu Lin, Sherali Zeadally, Tzung-Shi Chen, and Chih-Yung Chang, "Enabling Cyber-Physical Systems with Wireless Senso Networking Technologies," International Journal of Distributed Sensor Networks, Hindi, 2012.

[13] Tarang TM, Tarang-Product Manual-Melange System Pvt Ltd, www.melangesystems.com, 2010.

[14] Dr. N. Shekar V. Shet, Naveen Kumar Panguluri, Harsha MP and Abhishek MB, "Wireless Monitoring of Water Resources in a Campus,” International Engineering Symposium, Japan, 2017. 